\title{
Taking a New Perspective on Suffering and Death
}

Chris Tweedt

In New Theists, ed. Josh Rasmussen and Kevin Vallier, Routledge, chap. 4, pp. 47-58 (2019)

\begin{abstract}
There is a massive amount of severe suffering and death in the world, and much of this suffering and death is out of our control. The amount and severity of suffering and death in the world can be used to make an argument for (or elicit a reaction against) the existence of God: if God-an all-powerful, all-knowing, and all-good being-exists, God would not allow such massive amounts of suffering and death. I'll propose a line of response that begins by exploring what would be involved in taking a new perspective on the suffering and death in the world. I then argue that there is no good reason not to take that new perspective. If this is correct, the argument from (or reaction to) suffering and death to the conclusion that God doesn't exist has lost much of its force; an argument that seems forceful from one perspective is weak from a different perspective that is just as reasonable, or more reasonable, to take.
\end{abstract}

\section{Introduction}

Are the suffering and death in this world consistent with the existence of a good God? There is a massive amount of severe suffering and death in the world, much of which is out of our control. Let us call the pieces of information about the amount and severity of suffering and death "the data of suffering." As one reflects on the data of suffering, they might be tempted to reject the existence of God. If God - an all-powerful, all-knowing, and all-good being - exists, God would not allow such a massive amount of suffering and death.

A lot has been written on this argument or reaction, but typically responses come in two forms. The first form of response is a theodicy; this response attempts to provide some new evidence that exonerates God from allowing the amount and severity of suffering and death in the world. ${ }^{1}$ The second kind of response is skeptical theism; this response attempts to show that we cannot reasonably discern from the information we have whether or not God would allow the current amount and severity of suffering and death in the world. ${ }^{2}$

\footnotetext{
${ }^{1}$ For some examples of theodicies, see Hick 1978, Swinburne 1988, Swinburne 1996, and Adams 1999.

${ }^{2}$ To be sure, a skeptical theist is not simply a theist that is a skeptic; instead, skeptical theists are skeptical about our ability to discern God's reasons for suffering and death in the world. For some examples of skeptical theistic responses, see Bergmann 2001, Bergmann 2012, Wykstra 1996, van Inwagen 2006, Stump 2010, Alston 1991, Bergmann and Rea 2005, and Plantinga 1974.

${ }^{3}$ This language follows Kvanvig 2011. Gage 2014 argues that what we make of the evidence could itself be evidence. If this is so, we could perhaps think of what we make of the evidence as a different kind of evidence that is still worth distinguishing from the other evidence we have.

${ }^{4} \mathrm{By}$ "reasonable", I mean epistemically rational, which is commonly contrasted with practical rationality. Epistemic

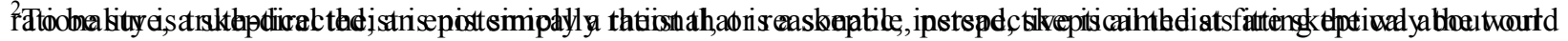
ability to discern God's reasons for suffering and death in the world. For some examples of skeptical theistic responses, see Bergmann 2001, Bergmann 2012, Wykstra 1996, van Inwagen 2006, Stump 2010, Alston 1991, Bergmann and Rea 2005, and Plantinga 1974.
} 
I will explore a new way to develop the second kind of response. This way of responding begins by making a distinction between the evidence one has and what one makes of that evidence. ${ }^{3}$ One way someone can make something of the evidence is to take a different perspective on that evidence. The response I'll propose involves first considering what one would think if one took a different perspective on one's evidence, which includes the data of suffering. To consider different perspectives, I'll contrast two kinds of perspectives one could take.

One kind of perspective on the data of suffering is what I will call "a theological perspective." On this kind of perspective, the data of suffering does not play as prominent of a role as they do on non-theological perspectives - the explanation for the data of suffering does not need to be as strong as it would be were one not to have a theological perspective, and even if one failed to discover an explanation for the data of suffering, God (if God exists) is not as culpable as God appears to be on a non-theological perspective. Another kind of perspective, which opposes the theological perspective, is what I will call "an atheological perspective." On this kind of perspective, the explanation for the data of suffering needs to be strong, and God (if God exists) is more culpable than God would be on a non-atheological perspective. These two perspectives occupy end points of a spectrum of perspectives; one can be closer to a thoroughgoing theological or a thoroughgoing atheological perspective. At this point, readers may wonder which perspective, if any, they have taken. To discover this, I ask the reader to wait until the end of the next section, where it is clearer what perspectives are and how to identify them.

In the next section (Section 2), I will motivate the idea that there are perspectives we can take on our evidence, describe what perspectives are (with examples), and argue that we inevitably take some kind of perspective (on the spectrum from theological to atheological perspectives) about information we have about the world, including the data of suffering. In Section 3, I'll argue that there aren't any good reasons for adopting the atheological perspective over the theological perspective. If this is correct, the argument from or reaction to the data of suffering to the conclusion that God doesn't exist has lost much of its force; an argument that seems forceful from one perspective is weak from a different perspective that is just as reasonable, or more reasonable, to take. ${ }^{4}$

\section{Taking a Perspective on the Data of Suffering}

In this section, I'll make the case that we need to take at least one kind of perspective (that is on the spectrum from theological to atheological perspectives) on the information we have about the world, including the data of suffering. I'll do this by first motivating the distinction between the evidence we have and what we make of it. Second, I'll give some examples of perspectives. Last, I'll show that we need to take one of these perspectives on the information we have about the

\footnotetext{
${ }^{3}$ This language follows Kvanvig 2011. Gage 2014 argues that what we make of the evidence could itself be evidence. If this is so, we could perhaps think of what we make of the evidence as a different kind of evidence that is still worth distinguishing from the other evidence we have.

${ }^{4}$ By "reasonable", I mean epistemically rational, which is commonly contrasted with practical rationality. Epistemic rationality is truth-directed; an epistemically rational, or reasonable, perspective is aimed at fitting the way the world is. There needs to be good truth-directed reasons to take a reasonable perspective. Practical rationality, on the other hand, is action-directed; a practically rational perspective is aimed at imposing something onto or into the world. There need only to be good action-directed reasons to take a practically rational perspective.
} 
world, including the data of suffering, and to take one of the perspectives is very likely to take a theological or atheological perspective.

\section{The distinction between the evidence you have and what you make of it}

The distinction between the evidence one has and what they make of it is facilitated by a view in epistemology called "Permissivism." ${ }^{5}$ Permissivists hold that two people can reasonably form different beliefs on the basis of the exact same evidence. ${ }^{6}$ For example, two jurors can have been presented with all the same evidence in a case, and after evaluating the evidence, one juror can reasonably believe that the defendant is guilty while the other reasonably believes the defendant is not. To be clear, Permissivism doesn't require that any of these people form any beliefs - it's a view about propositional justification, which is just to say that it's about what people could reasonably believe, whether or not they actually have already formed a belief about it. ${ }^{7}$

If two people have the same evidence and can form different reasonable beliefs, what is it besides the evidence that makes the difference between what they can reasonably believe? The answer: what they make of the evidence. Spelling this out, however, is more difficult, but some Permissivists have articulated different ways someone could make something of their evidence. Here are some proposals:

- There could be different reasonable standards for evaluating evidence. ${ }^{8}$ Whereas someone could be very stringent, another could have looser standards. The person with looser standards could reasonably accept and form a belief, because the evidence for it meets their standards, but since the evidence for the belief doesn't meet the stringent standards, it would be unreasonable for the person with those stringent standards to form the belief.

- There could be different reasonable prioritizations of knowledge-related goals. ${ }^{9}$ The usual knowledge-related goals are: 1) to believe truths and 2) to avoid falsehoods. We have to have both goals. If our goal is just to believe truths, we'll accomplish it by believing everything, which is way too permissive-we'll believe too many falsehoods. If our goal is to avoid falsehoods, we'll accomplish it by not believing anything, which is way too restrictive-we wouldn't believe any truths. Since we need both, we need to figure out which, if any, of these goals to prioritize. If we give greater priority to the truth-believing

\footnotetext{
${ }^{5}$ Defenders of Permissivism include Thomas Kelly 2013a, 2013b, Miriam Schoenfeld 2014, Jonathan Kvanvig 2011, 2014, Gideon Rosen 2001, and Nicole Garcia, manuscript. Opponents include Roger White 2005, David Christensen 2007, and Richard Feldman 2007.

${ }^{6}$ Or they could reasonably have different levels of confidence on the basis of the same evidence, even if their beliefs are the same. I will ignore this version of Permissivism in this paper to avoid unnecessary complexity.

${ }^{7}$ Propositional justification is a function from evidence to epistemic status, regardless of whether the subject believes the proposition. Doxastic justification is a property of beliefs wherein the propositional content of the belief is justified by the subject's evidence and, in addition, the subject is appropriately attentive to and rightly responsive to that evidence.

The view here, then, is about the epistemic status that a proposition has relative to a perspective whether or not any subjects have formed any beliefs about the proposition.

${ }^{8}$ Schoenfeld 2014.

${ }^{9}$ Kelly 2013a.
} 
goal, we'll be more permissive about what we believe than those who give greater priority to the avoid-falsehood goal.

So, according to Permissivism, two people can have exactly the same evidence, but because of what they make of the evidence - their different standards for evaluating evidence or their different knowledge-related goals — they can each form different and reasonable beliefs. ${ }^{10}$

The position I'm advocating here does not require Permissivism to be true. All it requires is that we make a distinction between what the evidence is and what one makes of it. It could be true that there is only one reasonable way to make something of the evidence even if Permissivism is false. The view that Permissivism opposes - Uniqueness - is the view that, given the same body of evidence, there is exactly one belief that is reasonable for anyone with that evidence to have. One way to understand this Permissivism-opposing view is that there is only one reasonable way to make something of the evidence. If there's only one reasonable way to make something of the evidence, then, given the same body of evidence, there will be only one belief that's reasonable for the person with that evidence to have. The main point here is that even if Permissivism is false, we can recognize a distinction between the evidence and what we make of it, and that distinction is all that's required for the view advocated here.

\section{Examples of perspectives}

Before giving examples of perspectives, I should make clear that the position proposed here only requires that we can take a perspective on our evidence when the beliefs we would form are value judgments. By value judgments, I mean the kinds of judgments we make after evaluating or making an assessment of our evidence. The following are some examples of value judgments:

- A college degree is worth pursuing.

- She's a good person.

- Retiring by 60 is an important goal to have.

- Your contributions to tech stocks are promising investments.

All of the above examples would involve not only receiving evidence but also evaluating it to make an assessment. For example, it requires not just observation about receiving college degrees but also an assessment to make the judgment that a college degree is worthwhile. The following are not value judgments:

- $2+2=4$.

- The iPhone was first released in 2007.

- She's five feet tall.

- Amazon's stock rose $27 \%$ in 2015.

There are, of course, statements for which it's unclear whether they belong in the first or second list - it's difficult to tell whether some beliefs involve evaluating or assessing data - but the specific beliefs relevant to this article are not unclear cases. They clearly involve value judgments about God:

- God is a moral monster.

\footnotetext{
${ }^{10}$ It is worth reiterating note 2 here: someone could object by saying that what one makes of the evidence could itself be evidence. If this is so, we could perhaps think of what we make of the evidence as a different kind of evidence that is still worth distinguishing from the other evidence we have. The objection, then, turns on a terminological difference that need not detract us here.
} 
- God, if in existence at all, is not good.

- God isn't the kind of being that could have allowed all of this.

- Nothing in the future could possibly make up for all of this.

Those judgments are the kinds of judgments that lead to the conclusion that God does not exist in the argument from suffering - for example, one might think that God would not allow the current amount and severity of suffering and death, because if God did, then God would be a moral monster, and since God cannot exist and be a moral monster, God doesn't exist at all.

For our purposes here, suppose that we can only take a perspective when we make value judgments. To show what a perspective is, I'll give some examples (different from the Permissivist examples above) of different perspectives one could take.

1. Event Selection: When someone tells a story of their lives, they need to select some events to include and some to exclude. The selected events are the important ones building to the climax of the story. For some examples, someone could select events that best describe their career path, their character development, or the trajectory of their romantic relationships, each of which are based on the same information about that person's life. The difference is in which events the storytellers take to be important for the story, and, as a result, different stories have different climaxes of the person's life.

2. Optimism/Pessimism: Due to differences in hopes and outlooks on life events, an optimist might think a moderately risky career path is worth pursuing, whereas a pessimist may emphasize all the potential failures and think it's not, even though the information provided to each person is the same.

3. Punishment/No Reward: Some aspects of a situation are easier to focus on than others, and this difference in focus may lead to different value judgments. For an illustration, take the following sets of statements:

A. Parent: "We'll go to the zoo today only if you clean your room."

B. Parent: "If you don't clean your room, you'll lose your zoo privileges for the day."

A. Boss: "I'll give you a $\$ 1,000$ bonus if you meet your deadline this quarter."

B. Boss: "I'll give you a $\$ 1,000$ bonus unless you fail to meet your deadlines this quarter."

Both A/B pairs have the same practical consequence. In the first A/B pair, the child doesn't get to go to the zoo if he doesn't clean his room. In the second A/B pair, the employee receives a bonus if she meets her deadlines. The difference between the $\mathrm{A}$ statements and the B statements is just a difference in focus. The A statements focus on the receiving of the benefit (zoo trip $/ \$ 1,000$ ) and treat it like a reward, whereas the B statements focus on losing the benefit and treat losing it like a punishment.

Similarly, someone may look at their life events and see themselves as just not being rewarded with extra benefits, whereas someone else may look at the same events and 
see themselves as missing what they thought they deserved. These people disagree about whether the good events were theirs to lose.

\section{The need to take a theological or atheological perspective}

In all of the above cases, one cannot help but take a perspective on their evidence. When we tell a story, we have to choose certain events to highlight, and which events we choose is based on our perspective. When we evaluate whether an event is worth pursuing, we have to make that judgment on the basis of some future outlook. And, finally, when we make an assessment of whether we are being rewarded or punished, we have to focus on some aspect of the situation. Further, in all of these cases, taking a different perspective doesn't involve adding any more evidence than is had by the person taking the other perspective. ${ }^{11}$ It just involves seeing the same evidence differently.

The three examples of differences in perspectives above apply specifically to judgments we could make about God. Here's how:

1. Event Selection: When someone tells the story of the world, they could emphasize the data of suffering and conclude that the world has been in demise since its beginning, selecting as most important the events those that involve intense suffering (survival of the fittest, massively fatal diseases, religious wars, etc.). Or, instead, that person could select events that highlight flourishing, triumph, and accomplishment in the world, seeing the data of suffering as a byproduct of or means to flourishing, triumph, or accomplishment.

2. Optimism/Pessimism: A pessimist could interpret the data of suffering as something unredeemable, thus part of a world that is not worth creating. Or, instead, an optimist could interpret the data of suffering as something that is for the sake of something better, perhaps an opportunity for human solidarity or the beginnings of a world that will get better, even if the optimist does not know what exactly the suffering is for the sake of.

3. Punishment/No reward: Someone could focus on the data of suffering and see themselves as having lost what is due to them so that God is wrong to take away what is owed to them. Or, instead, someone could focus on the events characterized by flourishing and see those as rewards, events that are not owed to them.

So, we must take a perspective on the information we have about the world, including the data of suffering. On one kind of perspective - an atheological perspective - the data of suffering is prominent, and, due at least in part to that person's perspective, the good things about this world aren't as prominent and so are barely relevant to the formation of beliefs about God. Instead, the data regarding the magnitude, duration, distribution, and severity of suffering is some of the most prominent evidence, and any explanation aimed at vindicating God in light of the data of suffering needs to be very strong.

\footnotetext{
${ }^{11}$ Even if taking a different perspective were to result in having more evidence than one with another perspective, the additional evidence would be the result of taking the different perspective, not the other way around.
} 
On the theological perspective, however, the good things about this world are prominent. They are the highlights of the story of the world, indicators that suffering is for the sake of something better, or undeserved benefits rather than what is owed to us by God. On this perspective, because the data of suffering are not as prominent, it will be easier for those with the theological perspective to accept explanations aimed at vindicating God in spite of the data of suffering than it would be on the atheological perspective.

At this point, the reader might be able to identify what kind of perspective they take and how close it is to an endpoint on the atheological/theological spectrum. If the reader is still unsure, however, the reader could ask themselves the following questions, affirmative answers to which are evidence that the reader has taken a perspective toward the atheological end of the spectrum.

1. When I describe the history of the world, do I mention suffering or pain?

2. When I describe the suffering in the world, do I use a term that impugns the character of God, if God exists? For example, do I describe the suffering as "monstrous," "unconscionable," or "malicious"?

3. Do I have a visceral reaction of hatred or resentment toward God when I think about the suffering in the world?

4. If someone tries to give reasons why God could have justifiably allowed certain kinds of suffering or pain, do I think they're probably not going to be able to offer an explanation that is strong enough to convince you otherwise?

5. When thinking about the suffering in the world, do I think there could never be any explanation that God could have for allowing it, even one that I haven't considered?

6. Is it impossible that any evidence for God's existence would lead me to think that God exists despite the suffering in the world?

\section{Reflection on the Other Kind of Perspective}

Is it more reasonable to take an atheological perspective than a theological perspective? Perhaps reflection on the perspectives will reveal that it isn't. Perhaps a theological perspective is just as reasonable - or more reasonable - than any atheological perspective. If someone with an atheological perspective is aware that a different perspective is just as, or more, reasonable than their own, then, plausibly, they should reduce their confidence in the negative value judgment they make about God on the basis of that perspective (that is, in the kind of value judgment that is so negative that explanations aimed at vindicating God need to be very strong). To the person taking the atheological perspective, the fact that someone else has a different but reasonable perspective on the exact same evidence and forms an opposing belief should at least make that person more hesitant to make the kind of negative value judgments that result from their perspective.

For example, suppose someone scoffs at a family that uses government assistance (food stamps and other government welfare). The scoffer might have a perspective according to which he sees those who accept government assistance as a drain on the system and as taking advantage of those who put in honest work, and he can likewise see the government as enabling laziness. Then, when the scoffer loses his job and needs to receive government assistance to make ends 
meet, his perspective could change. He could see those on government assistance as in need of help rather than taking advantage of a system, and he could likewise see the government as assisting someone who needs it rather than enabling laziness. The person on government assistance might later return to seeing those on assistance as taking advantage of the system, but that person is less likely to be as confident about that judgment when he knows that there was a reasonable perspective according to which they are not taking advantage of the system.

In a similar way, perhaps someone scoffs at a God who creates a world that includes the data of suffering. The scoffer might have a perspective according to which a God that creates that world is a moral monster, or at least God is not the kind of being that could have allowed all of this suffering. Then, perhaps the scoffer could consider a different perspective-a perspective that highlights the good things about this world rather than the suffering, sees suffering as something that is for the sake of something better, or sees the absence of suffering as something that is not owed to us. Perhaps that person would then see God as a good—or at least a morally acceptable - being rather than a moral monster. The person might later return to seeing God as morally deficient, but that person is less likely to be as confident or vehement about that judgment when that person knows that there as a reasonable perspective according to which God is not morally deficient.

The question we can thus ask ourselves is: which kinds of perspectives are more reasonable to take? It would be nice to have a perspective-neutral way of figuring out the answer. It is, however, difficult to find a criterion we can use to tell whether taking an atheological perspective is more reasonable than taking a theological perspective. ${ }^{12}$ There are some criteria that are used to help adjudicate which of two theories is more reasonable: simplicity, explanatory power, proximity to the ideal theory, whether the theory fits with the obvious data, and others. But these criteria don't apply to perspectives.

- With respect to simplicity, the theological perspective is not more complex than the atheological perspective. In fact, it is difficult to figure out what could even make a theological perspective more complex than an atheological one. A theological perspective is not more complex by virtue of the number of statements that would ideally describe it, because in an ideal description of each perspective, plausibly the same number of statements would make up each description. Further, a theological perspective does not require that more entities exist, because someone can have a theological perspective without thinking that God exists. For example, someone could think that God does not exist, but if God exists, God would not be morally deficient for allowing the suffering that there is in this world. (Note that the issue here is not whether theism is more complex than atheism. The issue is whether one perspective is more complex than another.)

- A theory has explanatory power if it best explains the relevant data, but what the relevant data are is determined by the perspective one takes, and both the theological and atheological perspectives seem to do an adequate job of explaining the data that are relevant according to those respective perspectives.

- We could adjudicate which of the perspectives is the most reasonable by comparing the beliefs one ends up with on those perspectives with the beliefs one

\footnotetext{
${ }^{12}$ It is unreasonable to think that the theological is less reasonable just because one happens to hold the atheological perspective. That kind of procedure will lead one never to give up their beliefs. I don't address this approach further.
} 
would end up if they were to have an ideal perspective, but it's not clear that there is an ideal perspective, or if there is, it's not clear what it is. One might be tempted to think the ideal perspective is to take all of the evidence as equally prominent, but it's not clear we should take all of our evidence as equally prominent. Similarly, one might think that an ideal perspective takes some theistic evidence into account and some atheistic evidence into account to counterbalance it. But whether evidence is theistic or atheistic is, at least in part, determined by one's perspective, and whether we take a particular piece of evidence seriously is also determined by one's perspective. Until we know what evidence we should take to be most prominent (if there is some evidence one should take that way), we don't have a way of determining which of the two perspectives are closer to the comparison perspective.

- With respect to fitting with the obvious data, both the atheological and theological perspectives fit the obvious data; they both use the same data.

As it stands, then, there seems not to be perspective-neutral general criteria to determine what perspective is most reasonable. We could, of course, evaluate which perspective is reasonable according to a different perspective, but then when we can ask the further question: is that perspective more reasonable than one that results in a different conclusion? That just pushes our issue back further. ${ }^{13}$

There may be other criteria on which perspectives are more reasonable than others, but it's hard to see what these criteria are, and even if we were to discover and articulate them, it's difficult to see how they would make the theological perspective any less reasonable than the atheological perspective. We may leave this as an open inquiry for the reader. Are there general criteria on which the atheological perspective is more reasonable? As of now, at least, no such criteria have been established.

Of course, some perspectives are obviously unreasonable, and it's consistent with the above analysis that some perspectives are reasonable while some aren't. The proposal I'm defending here only requires that the theological perspective isn't obviously unreasonable. As long as the theological perspective isn't obviously unreasonable, it's a candidate for being a reasonable perspective, and since it's a candidate, it's difficult to find a way to determine whether it is less reasonable than the atheological perspective.

So far I've only addressed epistemic reasons to think one perspective is more reasonable, but there are practical reasons for taking the theological perspective over the atheological perspective. These reasons are the same as the reasons for selecting positive events as most important when telling a story, for retaining an optimistic outlook, and for not taking oneself to

\footnotetext{
${ }^{13}$ Kvanvig 2014 argues for a way in which one can reasonably take a perspective even if there is no perspectiveneutral way of adjudicating which perspective is most reasonable - one can assess the reasonableness of one perspective by using another, perhaps different, perspective, and eventually the reflection must stop; one cannot reflect an infinite number of times. I hope to have shown that if reflective subjects were to become aware that there are reasonable but opposing perspectives without a theory-based criterion for adjudicating which is more reasonable, either the subject would have additional evidence to consider or the awareness would influence the subject's higherorder perspectives such that the subject should adjust their beliefs more toward the direction of the opposing perspective. The government-assistance example above was meant to show how recognition of an opposing perspective could alter one's beliefs in a reasonable way.
} 
be entitled to not suffer but rather to see not suffering as an undeserved benefit. I am not going to take a stance on whether these practical reasons are reasons one should adopt, because the main purpose here was to show that by using our best theory-based resources, we don't have a way to determine that the atheological perspective is more reasonable than the theological perspective.

\section{Conclusion}

I have offered a way to reconsider of the problem of suffering. If what I've said above is correct, two people can have all the same evidence - information about the world, including the data of suffering - but their perspectives can lead them to form different value judgments about God on the basis of that shared evidence. Further, it may very well be just as (or more) reasonable to take a perspective according to which God is judged positively as it is to take a perspective according to which God is judged negatively. So, the argument from suffering, which seems forceful from one perspective, is weak from a different perspective that is just as reasonable to take. As in the government assistance example, when one learns of another just-as-reasonable perspective, that new knowledge should at least lead one to be less forceful in their negative value judgments, and in this case, their negative value judgments about God.

I recognize that different people will weigh the reasonableness of various perspectives differently. Not everyone will think it possible to consider a different perspective, especially not one so different than one's current perspective, and some will think that the theological perspective is obviously unreasonable (but why?). I encourage the reader to take some time to try to adopt different perspective on the data of suffering. Since it is at least just as reasonable to take the theological as the atheological perspective, if one were to adopt a different perspective, it would, on that perspective, be reasonable for one to think that the data of suffering doesn't support the premise that God is a moral monster as strongly as it once did. When this consideration is combined with theodicists' or skeptical theists' additional responses, perhaps those responses will tip the scales so that one will be convinced that the argument from suffering is not ultimately successful. 


\section{Bibliography}

Adams, Marilyn McCord. Horrendous Evils and the Goodness of God. Cornell University Press, 1999.

Alston, William. "The Inductive Argument from Evil and the Human Cognitive Condition," Philosophical Perspectives 5, 1991: 29-67. Reprinted in Howard-Snyder 1996, $97-125$.

Bergmann, Michael. "Skeptical Theism and Rowe's New Evidential Argument from Evil," Nous 35, 2001: 278-296.

Bergmann, Michael. "Commonsense Skeptical Theism," in Clark, Kelly and Michael Rea (eds.), Science, Religion, and Metaphysics: New Essays on the Philosophy of Alvin Plantinga. Oxford University Press, 2012.

Bergmann, Michael and Michael Rea. "In Defence of Sceptical Theism: A Reply to Almeida and Oppy," Australasian Journal of Philosophy 83(2), 2005: 241-251.

Christensen, David. "Epistemology of Disagreement: The Good News." Philosophical Review 116:2, 2007: 187-217.

Feldman, Richard. "Reasonable Religious Disagreements." In Philosophers without Gods, ed. Louise Antony. Oxford: Oxford University Press, 2007: 194-214.

Gage, Logan. "Evidence and What We Make of It," Southwest Philosophy Review 30(2), 2014: 89-99.

Hick, John. Evil and the God of Love. Harper and Row, 1966. Revised edition: 1978.

Kelly, Thomas. "Evidence Can Be Permissive," in Contemporary Debates in Epistemology (Second Edition), eds. Matthias Steup, John Turri, and Ernest Sosa. Wiley-Blackwell Publishing, 2013a: 298-311.

Kelly, Thomas. "How to be an Epistemic Permissivist", in Contemporary Debates in Epistemology (Second Edition), eds. Matthias Steup, John Turri, and Ernest Sosa. WileyBlackwell Publishing, $2013 \mathrm{~b}$.

Kvanvig, Jonathan. "The Rational Significance of Reflective Ascent," in Evidentialism and Its Discontents, ed. Trent Dougherty, Oxford University Press, 2011: 34-54.

Kvanvig, Jonathan. Rationality and Reflection. Oxford University Press, 2014.

Plantinga, Alvin. God, Freedom, and Evil. Harper and Row, 1974. 
Rosen, Gideon. "Nominalism, Naturalism, Epistemic Relativism," Philosophical Perspectives 15, 2001: 69-91.

Stump, Eleonore. Wandering in Darkness. Oxford University Press, 2010.

Swinburne, Richard. "Does Theism Need a Theodicy?" Canadian Journal of Philosophy 18, 1988: 287-312.

Swinburne, Richard. "Some Major Strands of Theodicy?" in Howard-Snyder, Daniel (ed.), The Evidential Argument from Evil. Indiana University Press, 1996: 30-48.

Schoenfeld, Miriam. "Permission to Believe: Why Permissivism is True and What it Tells Us about Irrelevant Influences on Belief," Nous 47:1, 2014: 193-218.

van Inwagen, Peter. The Problem of Evil. Oxford University Press, 2006.

White, Roger. "Epistemic Permissiveness,” Philosophical Perspectives 19, 2005.

Wykstra, Stephen. “"'Rowe's Noseeum Arguments from Evil,” in Howard-Snyder (ed.), The Evidential Argument from Evil. Indiana University Press, 1996: 126-150. 